\title{
MIDDLE SCHOOL STUDENTS' DIGITAL GAME EXPERIENCES IN THE CITY OF MAKKAH IN SAUDI ARABIA
}

\author{
Mohammed Alqurashi $^{1 \star}$, Yousef Almoslamani ${ }^{2}$, and Abdullah Alqahtani ${ }^{3}$ \\ ${ }^{1} \mathrm{PhD}$ candidate, University of Northern Colorado, The United States, alqu2479@bear.unco.edu \\ ${ }^{1} \mathrm{PhD}$ candidate, University of Northern Colorado, The United States, almo4590@bear.unco.edu \\ ${ }^{1} \mathrm{PhD}$ candidate, University of Northern Colorado, The United States, alqa0717@bear.unco.edu \\ ${ }^{*}$ Corresponding author
}

\begin{abstract}
The purpose of this quantitative study is to investigate middle school students' experiences with gaming in Makkah City in Saudi Arabia. This study described the current condition of video game usage and compared that depth of usage to current academic grade point average (GPA). Also, it showed the difference between gender, and students' age and described the types of video games and elements that attract students to play video games. There were 201 middle schools students from Makkah who participated in this study. The study found there was a significant relationship between hours spent playing video games and students' GPAs. They also showed a significant difference between gender in hours spent playing video games and that there was no significant statistical difference between the middle schools students' ages in hours spent playing video games. Additionally, male students were perceived to have higher positive attitudes toward video games than females. Finally, the results suggested that there are three underlying factors (competition, discover, and knowledge) that attract students to play video games.
\end{abstract}

Keywords: Education, video game, middle school.

\section{INTRODUCTION}

In recent years, technology has impacted the daily lives of humans and now plays a significant role for our futures (Ortega, 2012). Games are one of the important technologies that affect children and adolescents. Today, the impact of video games on the youth is similar to that of religion, political movements, music, and culture (Miller, 2008). Miller (2008) said "Outside the classroom, playing is one of the fundamental human activities, one of the first that human children develop together with talking, toddling, and relating to others" (p. 3). Video games have become the center of attention in all homes today (Miller, 2008). Video games include all modes of digital applications such as PlayStation, GameCube, Sega, and Xbox. Therefore, the concept of gaming has transferred from being a form of entertainment to a form of technological literacy.

The purpose of this quantitative study is to investigate students' experiences with gaming in middle school (from seventh to ninth grades) in Saudi Arabia. This study describes the current condition of video game usage and Grade Point Average (GPA). In general, this study identifies whether or not middle school 
students in Saudi Arabia play computer and video games at home and, if they play games, would integration of such technology be a good instructional strategy to implement. If there is a high percentage of game players and playing hours, then the integration of games in middle school curriculum may be a useful teaching strategy. There are some studies which examined specific educational games and proved their positive effects on students' learning (Sadiq, 2010; Aliefendic, 2013; Alharbi, 2010; Aljuhani, 2011). However, after examination of the literature, the researcher noted that there is not framework for the current situation for student experiences.

The results of this study could assist the Saudi Arabia Ministry of Education in focusing on the need for the use of educational video games in the classroom. The Ministry could then decide to provide technological equipment/software and professional development opportunities for educators to increase use of games in pedagogy. Moreover, this research could add value to a project currently underway in the Saudi Arabia Ministry of Education that is exploring digital content and interactive curriculum.

\section{LITERATURE REVIEW}

In this literature review, we analyzed previous studies and presented information related to the components of this study. The researchers introduced gaming, the rapid increase in game development and play, benefits of classroom game integration, gender issues in gaming, and provided information about the Saudi Arabia education system.

\subsection{Gaming}

Game is very flexible term and it is defined based on our experience. According to The Oxford English Dictionary (OED) the game is "a form of play or sport, especially a competitive one played according to rules and decided by skill, strength, or luck". Also, games are categorized to adoptive, interactive, problem solving, representative, story oriented and more (Prensky, 2001). Moreover, game is a group of organized rules that enable a playing mode frame of experience for adults (Miller, 2008). Based on the previous we can say, the game is a tool that came in many different shapes which has activity with role and is used for many reason.

On the other hand, video game defines as "a game played by electronically manipulating images displayed on a television screen" (OED). Further, playing game is certain activities like any natural activity for example eating or sleeping and the players apply their experience and culture in this activities (Miller, 2008).

There are many types of computer and video games: fighting, puzzles, sports, adventure, strategy games, and more (Christopher, 2011; Aljuhani, 2011). Based on the number of players, games are categorized to individual or group games (Christopher, 2011). For example, puzzle games and adventure game theories models can be played by only one player. On the other hand, more than one player games can play sports games and fighting games (Christopher, 2011).

Video games are the most popular form of entertainment in Arab countries (Qudair, 2011). Al-Hadlaq (2011) presented a study that identifies the advantages and disadvantages of playing video games as noted from students' attitudes in Riyadh City in Saudi Arabia. He discussed 18 reasons that drive students to play video games. Many others studies discussed the reasons for the popularity of playing games in Arabic countries (Al-Hadlaq, 2011; Qudair, 2011). These studies showed that there are eleven common reasons that attract students to video games. It is important to know the common factors that grab students' attention to the games when designing educational games. The eleven common reasons are: wining, competition, challenge, adventure, enjoyable, discover, imagination, fill my leisure time, curiosity, talent development, and intelligence development.

\subsection{Rapid Increase in Gaming}

Since 1996, computer games and video games have been developed three times faster than before. The games are not just for children, but many adults as well. Statistics showed that $35 \%$ of parents in the United States play games for their own entertainment. Entertainment Software Association (ESA) (2015) observed that there was a strong increase in game titles from 2002 to 2011. It is recorded that during 2013 more than 160 million games were sold that provided about $\$ 21$ billion in revenue (ESA, 2015). This demonstrates the importance of gaming to society and that it is worth exploring pedagogical applications of gaming.

\subsection{Benefits of Game Integration}

As previously noted, the concept of gaming has transferred from being a form of entertainment to a form of technological literacy. Researchers see that gaming plays an important role in visual literacy and technological literacy (Clark \& Ernst, 2009). 
Video games increase students' awareness and consciousness. It is evident in the fact that games play a central role in increasing students' intelligence quotients (IQ) (Miller, 2008). Computer and video games affect the psychomotor functions and decrease stress (Clark \& Ernst, 2009). Also, game play enhances logical thinking, analytical skills, movement, social skills, visual abilities, collaboration, and computing (Miller, 2008; Clark\& Ernst, 2009). In the classroom, when students are playing games, they form teams and make their own strategies to win games. They observe and analyze the critical points and try to avoid problems by thinking more critically next time (Ashton, 2011). Al-Hadlaq (2011) found that more than $80 \%$ of students agree that the video games have positive effects in learning. In contrast, about $73 \%$ expected video games could consume their time that will affect their learning achievement.

Hsu and Chion's (2011) research showed the games practice experience for students. The participants were students enrolled in a science teacher preparation program. The researchers found that more than $76 \%$ of participants play games more than four hours a week. The study also showed that digital games increased positive attitudes (Hsu \& Chion's, 2011).

In a study by Clark and Ernst (2009) $72 \%$ of participants agreed that outside classroom homework assignments using computer or video gaming could be useful for student learning. Also, about $77 \%$ agreed that video gaming could be used to combine and teach concepts of science, technology, and mathematics education.

Aliefendic (2013) conducted study in a northeast Texas school district that contained 156 fifth grade students. The researcher asked the students to use math educational video games. The study found there was a positive relationship between students' achievement on their final mathematics test scores and the amount of time students spent playing educational video games. In addition, there was a significant positive relationship between the points earned playing video games and students' performance on standardized tests (citation).

In Saudi Arabia, Alharbi (2010) conducted a study about the effect of educational video games on students' achievement in math for second grade male students in the city of Almadina. The researcher used a control group and an experimental group. The study found significant differences between the two groups in the posttest. Also, the results showed a significant difference between the pretest and posttest for the experimental group. The study recommended integration of educational games into classrooms as teaching methods to increase students' performance (Alharbi, 2010)

Aljuhani (2011) conducted an experimental study with 72 female students at a middle school in Jeddah City. The researcher examined educational games with an experimental group in an English language class. The study found that there was a statistical significant difference between the mean scores for the two groups on a posttest. It mentioned that the game had a positive effect on student performance and enhanced student learning. It was also pointed out that the students were very excited when the played the game. This high level of motivation is yet another positive aspect of game integration. As a result of this study, Aljuhani (2011) approached Saudi Arabia Ministry of Education about providing educational games for students.

Sadiq (2010) examined the online games impact for students' performance for undergraduate physics courses. The results of this study showed that providing online games in classrooms could enhance students' performance. Moreover, according to the Georgia Department of Education (2006) that games based learning of Mathematics (Geometry) in high school at Georgia State are improved students for learning. The results found that Game-based learning (GBL) of mathematics increased student performance. Lee and Kwon (2005) found achievement for students who play games in class improved more than students in a traditional classroom environment.

\subsection{Gender Issues in Gaming}

There is a different between genders in playing game. Commonly, male is willing to play video game more than female. (Miller, 2008). Also, there is a different between male and female game play choices (Miller, 2008; Aliefendic, 2013). Usually, males prefer fighting and sport games because they tend to have strong features when they play games. On the other hand, females prefer puzzle games because they prefer thinking more than fighting (Miller, 2008).

In a study conducted at a German secondary school, researchers examined game preferences related to a mental rotation test for performance and gender difference (Quaiser-Pohl, Geiser \& Lehmann, 2006). This study used three types of players: non-player, Action and simulation game players, and logic and skill training game play. So, the results found that the more than $81 \%$ of male prefer the "Action and simulation player" while female more than $82 \%$ prefer the "logic and skill training game play" (Quaiser-Pohl, Geiser \& 
Lehmann, 2006). Therefore, it indicated that males and females prefer different types of games.

\subsection{Saudi Arabia Education System}

The Saudi Arabia Ministry of Education is responsible of planning and supervision of education for three educational levels (Elementary - Middle - High). Male and female students are separated through all levels of education. In Makkah City, there are about 1537 schools which contain 338,243 students in all levels and of both genders (Statistical Reports, 2015).

The purpose of this quantitative study is to investigate middle school students' experiences with games in Makkah City in Saudi Arabia. This study showed the current condition of video game used and compared between hours spent playing video games and students' GPAs. Also, it showed the different between gender, and students' age in the hours spent playing video games. It discussed some students' attitudes toward video games. Moreover, it offered the desired types of video games for middle school students. Furthermore, it described the elements that attract middle school students to play video games.

\section{Research Questions}

1. Is there a correlation between hours spent playing video games and students' GPAs?

2. Is there a significant difference between gender in the numbers of hours video games are played?

3. Is there a significant difference between students' ages in the number of hours video games are played?

4. Is there a significant difference between male and female perspective toward video gaming?

5. Is there a significant difference between gender for the types of video games played?

6. What are the underlying factors or elements that attract students to play video games?

\section{METHODS}

\subsection{Participants}

Participants included 201 middle school students (seventh to ninth grades) in the city of Makkah in Saudi Arabia during 2015. There were 129 male students and 72 female students. The age of participants ranged from 12 to 16 years. The participants were selected from different schools in the city of Makkah in Saudi Arabia. The population was all middle school students in Makkah city, which totaled 82,426 students. The number of male students was 43,120 and the number of female students was 39,306 students ('Statistical Reports', 2014). The researchers used multistage cluster sampling to selected six middle schools randomly.

\subsection{Data Collection}

Quantitative methods were employed in this study. After determining the participants, an online questionnaire was used to investigate gaming usage. The goal of the questionnaire was to collect the number of hours students spend playing computer or video games and students' GPAs. The questionnaire consisted of four sections. The first section was about demographic information such as gender and age. The second section was about students' GPAs in the first semester of the school year (2014-2015) and about time spent playing video games. For the GPA question, participants were asked to choose one of $(A$, $B, C, D)$ where $(A)$ means excellent and represented 90 percent or higher and (B) means very good and represented between 80-90 percent and (C) means good and represented between 70-80 percent and (D) means poor and represented less than 70 percent. The third part contained questions about favorite computer and video games and the reasons for playing the games. The last part of survey contained eight questions assessing students' experiences with playing computer and video games. The question was based on a five-point Likert scale, in which each point was given a numerical value ranging from 1 to 5 ( $1=$ strongly disagree, 2 = disagree, 3 = neutral, 4 = Agree, 5 = strongly agree (see appendix A).

The questionnaire seemed very simple and clear and the researcher avoided using specialized jargon to be sure all students understood the items. The researchers used convenience sampling which means "the researcher selects participants because they are willing and available to be studied" (Creswell, 2012, p. 145). Researchers asked teachers to take students to the school's computer lab to respond the questionnaire. Also, researchers asked teachers to observe the students to complete the survey. 


\subsection{Data Analysis}

The data was collected using a questionnaire. After collecting the data, it was analyzed using quantitative methods. The obtained data from the questionnaire was uploaded to SPSS for statistical analysis. For the first question, Pearson's correlation coefficient was used to investigate the relationship between the hours spent playing video games and students' GPAs. Creswell, (2012) mentioned that "a correlational design in which the researcher is interested in the extent to which two variables (or more), where changes in one variable are reflected in changes in the other" (p. 340). After explaining the students' experiences with using games through a descriptive analysis, the second question was analyzed by using independent sample t-test because there was one dependent variable (the numbers of hours' video games are played) and two independent variables (Male, Female). The third question was analyzed by an ANOVA method because there was one dependent variable (the numbers of hours' video games are played) and three independent variables (Ages). Another ANOVA was conducted for fourth and fifth questions to find the differences between the gender's perspective toward video games and types of video games. Finally, the last question was answered by conducting an exploratory factor analysis which is considered a variable reduction method.

\section{RESULTS}

The researchers presented the results and analyses of two types of outcomes. The results and analyses of the demographic data included information about respondents' genders and ages. Then, the results and analyses were discussed and inferences made to answer the questions of this study.

\subsection{Demographics}

Participants' demographic characteristics showed that gender of participants included 129 (64\%) male and $72(36 \%)$ female students. Participants' age ranges were 12-13, $14-15$, and 16 or older. The majority, $57.2 \%$ were between $14-15$ years of age, and about $24.4 \%$ were between $12-13$ years of age, and the rest of them, $18.4 \%$ were 16 years or older.

\subsection{Hours of Play and GPA}

The students were asked about the time they spent playing video games during the week. The result shows that there $71 \%$ of students were playing video games fewer than 10 hours a week. Students who did not play and who were playing more than 20 hours a week were $10 \%$ each. The students were also asked about their GPAs in the first semester of the school year (2014-2015). Ninety-two students selected of (A), sixty-five students selected (B), forty-two students selected (C), and two students selected (D).

\subsection{Favourite Games}

The questionnaire showed five types of video games. The highest percentage selected was $32 \%$ for fighting games, then $25 \%$ for sports games, and adventure games were preferred by $20 \%$ of the respondents. However, $11 \%$ of students selected strategy games and just $6 \%$ chose puzzles games.

\subsection{Statistical Tests}

To answer the first question, correlation coefficient (Pearson $r$ ) was used to determine the correlation between hours spent playing games and students' GPAs. The results of the Pearson correlation showed that there was significant relationship because $p=0.007$ is less than the 0.05 level and $r=.188$. Although, the Pearson correlation was statistically significant, the relationship seemed weak with hours spent playing games explaining only $3.58 \%$ of the variance in GPA $(\mathrm{R} 2=.0358)$.

For the second question, the independent sample t-test method revealed that there is a significant difference between gender and hours spent playing video games. The result showed that $T(128,71)=2.36, p=0.019$. Fig. 1 represents the differences between genders. For the third question, there is no statistical significant difference between the middle schools students' ages and hours spent playing games since the result showed that $F(2,198)=2.6, p=0.077$. 


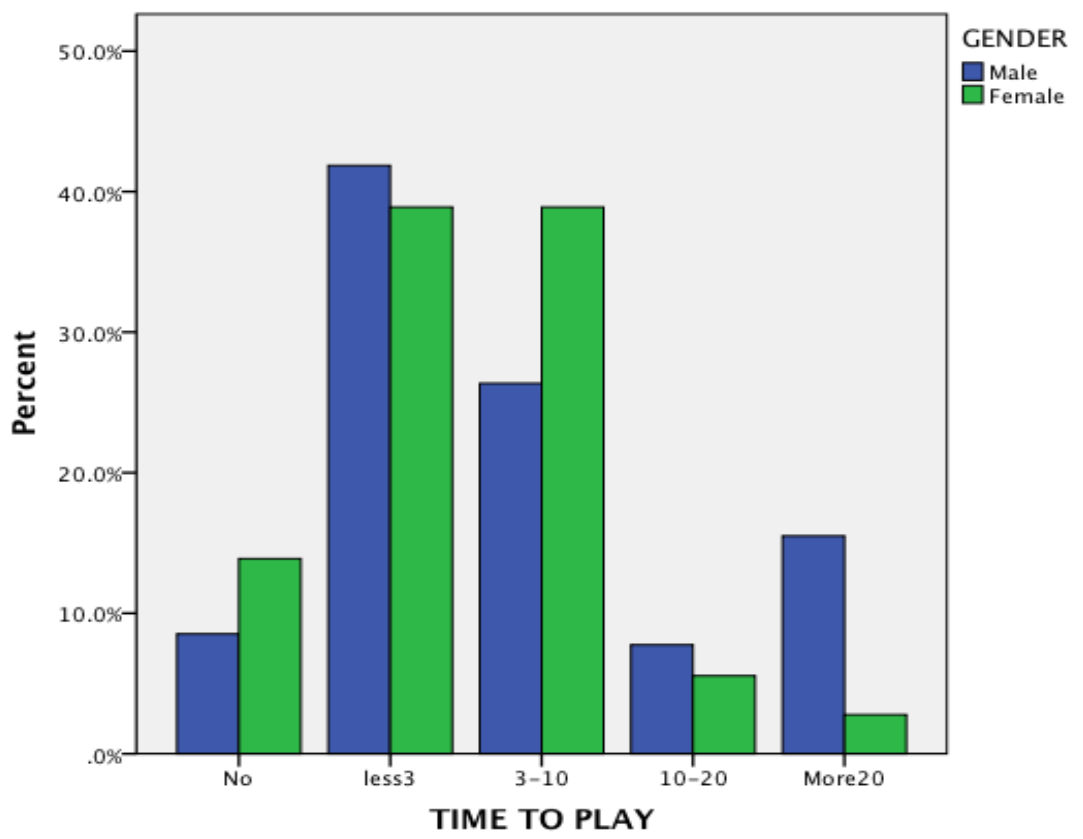

Fig.1. Hours of game play by gender

The fourth question regards the descriptive items. It was about the attitudes of Saudi students toward video games. The attitude subscale had eight items regarding the attitudes toward video games as we can see in Table.1.

Overall, the results showed that male students had more positive attitudes $(M=3.05)$ than female students $(F=2.94)$ toward video games. Both genders showed similar attitudes in six items. In contrast, there was a significant difference between genders in students' attitudes in two items that are 'playing games helps me to fill my leisure time', $T(128,71)=-2.2, p=0.028$ and 'I would like to play the video game alone', $T(128,71)=$ 2.57, $\mathrm{p}=0.011$ which are less than the 0.05 level.

\begin{tabular}{|l|c|c|c|c|}
\hline \multirow{2}{*}{ Items } & \multicolumn{2}{c|}{ Male } & \multicolumn{2}{c|}{ Female } \\
\cline { 2 - 5 } & $\mathrm{M}$ & $\mathrm{SD}$ & $\mathrm{M}$ & $\mathrm{SD}$ \\
\hline Playing games gives me a challenge & 4.20 & 1.06 & 4.04 & 1.18 \\
\hline Playing games allows me to cooperate & 3.92 & .98 & 3.60 & 1.18 \\
\hline Playing games helps me to develop useful skills & 4.05 & .94 & 3.89 & 1.06 \\
\hline Playing games helps me to develop useful knowledge & 3.74 & .99 & 3.88 & .94 \\
\hline Playing games helps me to fill my leisure time & 3.71 & 1.22 & 4.07 & 1.01 \\
\hline Playing games is exciting & 4.19 & .977 & 3.81 & 1.1 \\
\hline Playing games is enjoyable & 4.31 & .917 & 4.32 & .83 \\
\hline I would like to play the video game alone & 3.13 & 1.28 & 3.11 & 1.48 \\
\hline
\end{tabular}

Table 1. The Mean and Standard Deviation for eight Items.

For the types of video games, students selected: fighting games (32.2\%), puzzles games (10.6\%), sports games $(25 \%)$, adventure games $(20.6 \%)$, strategy games $(6.1 \%)$, and other games $(5.6 \%)$. As one can see in Fig. 2, the results showed that there was a significant mean difference between genders in the types of video games, $F(1,178)=6.28, p=0.013$, which is less than the 0.05 level. 


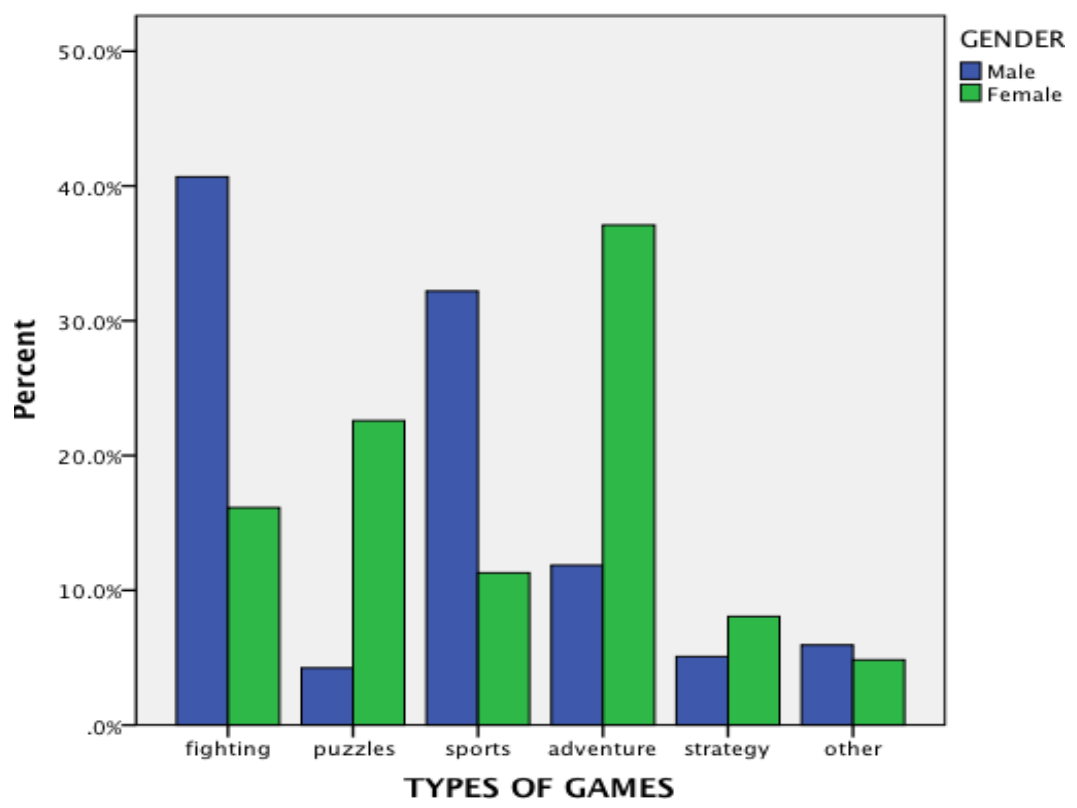

Fig.2. Games preference by gender

To answer the last question, a factor analysis was used to find the underlying factors or elements that attract students to play video games. Principal Axis Factoring (PAF) with varimax rotation showed that there were three common factors. These factors explained $41.8 \%$ of all variance. The eigenvalue for the first factor was 2.1 and explained $19.2 \%$ of the total variance, while the eigenvalue for the second factor was 1.3 and explained $11.4 \%$ of the total variance. The eigenvalue for the last factor was 1.2 and explained about 11.2 $\%$ of the total variance.

The first factor was called the competition factor because it has positive loadings for four variables as reasons for playing video games (win, competition, challenge, and adventure and enjoyable). The second factor was called discover factor because it has positive loadings for four variables as reasons for playing video games (discover, imagination, fill my leisure time, and curiosity). The last factor was called knowledge factor because it has positive loadings for two variables as reasons for playing video games (talent development and intelligence development).

\section{DISCUSSION AND CONCLUSION}

Although video games may push students into social isolation, which negatively affect mental, personal, and social growing, some educators and researchers encourage students to play games and they consider these games as a preventive treatment (Sharori, 2008). Some researchers consider that video games can improve the students' thinking skills and abilities (Sharori, 2008).

This study showed that there was a significantly positive relationship between students' GPAs and the amount of time they spent playing video games. This result agrees with Aliefendic's (2013) results about this relationship. This study's results may indicate that the video games effectively impact learning (Qudair, 2011). Furthermore, Al-Hadlaq (2011) asserts that students agree that video games have positive influence.

Although the results of this study indicated a positive relationship between students' GPAs and the amount of time they spent playing video games, this relationship not enough strong that hours spent playing games just explaining $3.58 \%$ of the variance in GPA. So, the researchers need to control other variables such as social, economic, and psychological variables.

This result demonstrated a significant difference in the mean between male and female students in the number of hours' games are played (male $=2.8$, female $=2.4$ ). This result was expected because many studies also found this difference (Qudair, 2011; Funk, 2003; Aliefendic, 2013). There are many reasons for these differences. First, the education system in Saudi Arabia is gender disaggregated; male and female students are separated through all levels of education which may affect gender access to technology. Second, it could be that many games were designed for male players (Aliefendic, 2013). Miller (2008) said "one of the arguments that often arises about girls and video games is that girls are not willing to devote as much time to playing as boys" (p. 63). Miller (2008) also stated "unfortunately, the current sophistication level of most video games cannot utilize girls' greatest weapons: communication and imagination" (p. 64). 
The aspect of the students' age results was not as significant as the other facets. For the student experience, the result illustrated that male students had higher attitudes toward video games than females. This difference is consistent with Alrasheedi's (2009) results which found that males have higher attitudes toward computers and technology. In general, both gender groups felt that playing games being enjoyable and gives them a challenge and allows them to cooperate and develop useful skills and knowledge and preferred to play video games alone. That agree with what Clark and Ernst (2009) mentioned in their study that $74 \%$ of the participants agreed that gaming is a valuable resource and learning tool for students. In contrast, while the female students felt that video games fill their leisure time more than male students, the male students believed more than female students that playing games is exciting.

There are many types of video games shown in this study: fighting games, puzzles games, sports games, adventure games, strategy games, and other games. People do differ in their games preferences (Malone, 1982). Fighting games have a higher percentage among all types of games. Some studies discovered that most students prefer fighting games (Qudair, 2011). Male students prefer fighting and sports games more than female students. The reason males prefer fighting games, as Miller (2008) mentioned, is that some characteristics present in fitting games use short-term memory and repeated actions. In contrast, female students prefer adventure games. Females are realistic and tend to solve problems without risk taking (Miller, 2008).

The last part was about the underlying elements that attract students to play video games. The findings for the last part are noteworthy because they drew a clear picture for the middle schools students' desires to play video games. The results showed that there are three underlying factors that attract students to video game play. Those factors were: competition, discovery and spending time, and knowledge. The male students tended towards factor one and factor two represented the female students' desires. Both genders were almost equal in factor three. According to Miller (2008), males seek to win or beat the video games, rather than simply playing for enjoyment. Video games should contain challenge elements because challenge is a strong motivator for students to play video games (Al-Hadlaq, 2011).

Based on this information, parents, educators, and the Saudi Arabia Ministry of Education should provide students with educational games that satisfy their desires for challenge and knowledge. Also, encourage programmers and designers to find a good content for the educational games that support Arabic language and culture. It is noted that the results in this study regarding the high levels of interest middle school students in Makkah City have in computer and video games, it is recommended that the Ministry of Education work with game producers to develop and provide educational games for students. The Ministry should gradually increase classroom use of games through assisting educators in understanding effective integration methods. Finally, this data will be useful for making decisions to use games in education for good, interactive content and teaching approaches.

A limitation of this study regards the degree to which generalizations can be made. Since the purpose of this study was to investigate the students' experiences in digital gaming in middle school in Makkah City in Saudi Arabia, the participants of this study only included public school students from that one city.

There are many recommendations for future research on similar topics. Future studies may need to examine other variables such as students' economic status, social status, and instructors' teaching styles. Moreover, as the study was limited to the city of Makkah in S.A, it is recommended to replicated and extended this study to other cities in Saudi Arabia. Also, since the sample study was chosen only among middle school students, future studies may involving all educational levels. The recommendations' study may generalize the result to the whole country.

\section{REFERENCE LIST}

Al-Hadlaq, A. A. (2011). The advantages and disadvantages of playing electronic games and motives of the playing from the viewpoints of public education students in Riyadh city. King Saud University.

Alharbi, O. M. (2010). The effectiveness of the instructional electronic games on academic achievement in Math course (Unpublished doctoral dissertation). Umm AIQura University, Makkah, Saudi Arabia.

Aliefendic, J. (2013). The correlation between the time spent playing educational video games and students' performance on standardized mathematics tests by fifth-grade students (Doctoral dissertation). Retrieved from ProQuest. (3595266)

Aljuhani, A. S. (2011). The effectiveness of the instructional electronic games on academic achievement in English course for the students of Intermediate level (Unpublished master thesis). King Abdulaziz University, Jeddah, Saudi Arabia. 
Alrasheedi, H. (2009). Information and Communication Technology (ICT): Effects of Gender and Training among Kuwait Teachers (Doctoral dissertation). Retrieved from ProQuest.

Ashton, D. (2011). Play stations and workstations: Identifying and negotiating digital games work. Information Technology \& People, 24(1), 10-25.

Christopher, T. V. (2011). Using game theory techniques and concepts to develop proprietary models for use in intelligent games (Doctoral dissertation). Retrieved from ProQuest. (AAI3450446)

Clark, A. C., \& Ernst, J. V. (2009). Gaming in technology education. The Technology Teacher, 68(5), 21-26.

Creswell, J. W. (2012). Educational research: Planning, conducting, and evaluating quantitative and qualitative research (4th ed.). Upper Saddle River, NJ: Pearson Education.

Entertainment Software Association (ESA). (2015). Overview. Retrieved from http://www.theesa.com accessed on February 25, 2015.

Funk, J. B. (1993). Reevaluating the impact of video games. Clinical Pediatrics, 32(2), 86-90.

Video Game. (n.d.). In Oxford English dictionary (OED). Retrieved from: http://www.oed.com/view/Entry/223262?redirectedFrom=video+game\#eid15555246

Georgia Department of Education (2006). Georgia Performance Standards Mathematics I. Retrieved from: https://www.georgiastandards.org/Standards/Pages/BrowseStandards/MathStandards9-12.aspx

Hsu, T. Y., \& Chiou, G. F. (2011). Preservice science teachers' prior game play experience and their perceptions of digital game-supported learning. In T. Bastiaens \& M. Ebner (Eds.), Proceedings of World Conference on Educational Multimedia, Hypermedia and Telecommunications 2011. Chesapeake, VA: AACE. 3331-3339.

Lee, I., \& Kwon, H. J. (2005). Relations among flow, information processing strategies, and performance in a computer-based simulation game. In P. Kommers \& G. Richards (Eds.), Proceedings of World Conference on Educational Multimedia, Hypermedia and Telecommunications. Chesapeake, VA: AACE. 986-992.

Malone, T. W. (1981). Toward a theory of intrinsically motivating instruction. Cognitive Science, 5(4), 333369.

Miller, C. T. (2008). Games: Purpose and potential in education. New York: Springer.

Ministry of Education in Saudi Arabia. (March 13, 2014). Statistical Reports. Retrieved from http://www.makkahedu.gov.sa/ehsaa/

Ortega, M. (2012). Technology in the educational setting past present and future. Proceedings of Society for Information Technology \& Teacher Education International Conference 2012 (pp. 4281-4284). Chesapeake, VA: AACE.

Prensky, M. (2001). Fun, play and games: What makes games engaging. In M. Prensky (Ed.), Digital gamebased learning (pp. 16-47). New York, NY: McGraw-Hill.

Quaiser-Pohl, C., Geiser, C., \& Lehmann, W. (2006). The relationship between computer-game preference, gender, and mental-rotation ability. Personality and Individual Differences, 40(3), 609-619.

Qudair, M. (2011). The Impact Of Electronic Games On Children Behavior (Unpublished master thesis). Algeria University, Algeria.

Sadiq, I. (2010). Effects of online games on student performance in undergraduate physics. In Proceedings of World Conference on Educational Multimedia, Hypermedia and Telecommunications 2010. Chesapeake, VA: AACE. 3685-3691

Sharori, M. (2008). Electronic games in global age pros \& cons. Amman, Jordan: Almassira. 